\title{
PLANEJAMENTO ORGANIZACIONAL - simplificando o raciocínio lógico do planejamento com a abordagem do PMI
}

\author{
Planeamiento organizacional - la simplificación de la lógica de planificación \\ con el PMI
}

\author{
Edelvino Razzolini Filho, Dr. Professor (razzolini@ufpr.br) \\ Egon Walter Wildauer, Dr. Professor (egon@ufpr.br) \\ José Simão de Paulo Pinto, Dr. Professor (simao@ufpr.br) \\ Universidade Federal do Paraná - UFPR \\ Departamento de Ciência e Gestão da Informação - DECIGI
}

Av. Pref. Lothário Meissner, 632 - $1^{\circ}$ andar - Campus III - Jardim Botânico

\section{RESUMO}

Este trabalho apresenta o uso de técnicas de gestão, baseadas no processo do Project Management Institute - PMI, para facilitar o desenvolvimento do processo de planejamento de atividades que proporcionem continuidade da prestação de serviços e da oferta de produtos de uma organização ao mercado. Baseia-se no mérito dos elementos que compõem o raciocínio estratégico, tático e operacional, abordando fases seqüenciais, contínuas, sob visão de processos e da respectiva melhoria contínua das suas tarefas (ações). O gerenciamento dos processos é o elemento central, agregador de valor e que responde pela correta identificação da qualidade sugerida, mediante mecanismos de monitoramento. A partir de análise do processo de planejamento em uma empresa do ramo de distribuição de produtos farmacêuticos, em dois momentos distintos, foi possível perceber melhorias a partir da adoção de um modelo como o que se propõe neste trabalho. Os resultados alcançados caracterizam o uso do método por se tratar da busca da melhoria como ação agregadora dos processos, exigindo as inferências de comprometimento, compromisso e atitude do gestor. A garantia da melhoria dos processos e das metas alcançadas resulta muito no reflexo do comportamento e maturidade da gerência, dos fatores que influenciam as tomadas de decisões, tendo sempre o profissional a avaliação e resposta final da ação a ser executada.

Palavras-Chave: Gestão, Planejamento, Tomada de Decisão, Melhoria Contínua, Gerenciamento de Processos. 


\begin{abstract}
This work shows management techniques based on Project Management Institute suggestions as a way to improve development of processes that will facilitate continuity of products and services an organization offers to the market. Its based on strategic, tactic and operational thinking as merit elements in sequential and continuous phases, under continuous improvement and better tasks processes design (actions). Process management is the way to add value and measure and monitor quality. From initial analysis of the planning of distribution process in an arm of pharmaceutical products company's, at two different times, it was possible to see improvements from the adoption of a model such as that proposed in this paper. Results shows improvement and action-valued processes, requiring inferences of involvement, commitment and attitude of the manager. Behavior reflexion and maturity of management, the factors that influence decision making and the final response action to be performed, assures that process goals and results improvement are achieved as planned.
\end{abstract}

Keywords: Management, Planning, Decision Making, Continuous Improvement, Process Management.

\title{
INTRODUÇÃO
}

"Dê-me uma alavanca e moverei o mundo!" Foi com essa frase de efeito que Arquimedes de Siracusa iniciou seu processo investigatório das forças da natureza. Da mesma forma, um gestor pode utilizar ferramentas para implantar uma nova forma de planejar os rumos que sua organização tomará, faz-se necessário o estudo investigatório e pormenorizado das ações a serem realizadas para vislumbrar o objetivo que deseja alcançar.

Os objetivos organizacionais, se claramente definidos, remetem à definição clara e precisa das atividades a interpretar como tarefa, sendo as ações o ponto crucial de uma boa estruturação de táticas, estas provenientes de estratégias elaboradas, embasadas e alavancadas pela visão do seu gestor no documento resultante do esforço de planejamento.

O gestor então se depara com uma gama de conceitos e ferramentas que o levam a refletir sobre a metodologia a ser utilizada para iniciar o processo de planejamento das ações que levem a atingir o objetivo proposto. Gerir passa a ser então a ordem do dia e faz parte do planejamento.

REBRAE. Revista Brasileira de Estratégia, Curitiba, v. 1, n. 3, p. 343-352, jan./abr. 2008 
Definir planejamento leva a uma discussão antiga, referenciando muitas teorias e muitos autores que concordam que não é simplesmente uma parte do processo administrativo, e sim o responsável pela definição do curso de ações a serem desenvolvidas (VALLE et.al., 2007). Para os objetivos do presente trabalho define-se planejamento como o processo por meio do qual se estabelecem objetivos, discutem-se expectativas de ocorrências de situações previstas, veiculam-se informações e comunicam-se resultados pretendidos entre pessoas, unidades de trabalho, departamentos de uma empresa e, mesmo, entre empresas (LIMMER, 1997, p.15).

Este trabalho apresenta uma abordagem para facilitar a elaboração de uma sequência lógica ao ato de planejar uma organização, considerando os principais elementos que o compõe, bem como a ordem de importância relativa à etapa e aos resultados esperados de cada uma dessas etapas, a partir da abordagem do PMI (Project Management Institute), acrescida de análise informacional prévia ao processo. Tais tarefas definem a estrutura de divisão de tarefas, conhecida como WBS (Work Breakdown Structure), que identifica as tarefas individuais requeridas para atingir-se um objetivo (HARWARD COLLEGE, 1997, p. $3)$.

O acréscimo de análise informacional prévia implica na utilização de ferramentas de análise ambiental (interna e externa) mas, sobretudo de contato com os usuários das informações resultantes do processo para que, seja possível fornecer a esses usuários as informações realmente relevantes ao processo de tomada de decisões.

\section{A LÓGICA DO PLANEJAMENTO}

A lógica aplicada ao processo desta metodologia de planejamento considera inicialmente os elementos que descrevem os requisitos e premissas da organização, interna e externa ao seu ambiente, bem como os preconizados por Porter (2005) quando sugere a inclusão dos clientes, fornecedores, concorrentes, produtos/serviços substitutos ou novos entrantes no mercado em uma análise ambiental da indústria, antes mesmo da formulação de estratégias defensivas que posicionem a empresa em uma situação de competição favorável.

Importante destacar que a reatividade caracteriza a maioria das organizações, ou seja, quando afetadas por situações ambientais (internas ou externas), as organizações reagem com intervenções ao alcance dos recursos disponíveis. Por outro lado, as organizações que ocupam

REBRAE. Revista Brasileira de Estratégia, Curitiba, v. 1, n. 3, p. 343-352, jan./abr. 2008 
posições de destaque em suas áreas de atuação, são aquelas com comportamento mais próativo, ou seja, aquelas que com o uso de ferramentas de análise ambiental antecipam-se às situações intervindo no ambiente com o objetivo de obter vantagem competitiva.

Porter (2005) continua enfatizando que o diagnóstico da situação atual da organização deve ser o mais correto e fiel possível à realidade vivida pela mesma, considerando o uso de ferramentas, como SWOT ou BSC, que descrevam seus pontos positivos, negativos, sugira pontos que possam ser melhorados, bem como aqueles que são, ou podem, tornar-se fortes ameaças a ações futuras.

A análise SWOT (Strength, Weakness, Opportunnities and Threads) preconizada por Andrews e Christensen, é uma ferramenta útil ao planejamento por propor o mapeamento e descrição detalhada dos elementos que identificam claramente os pontos fortes, pontos fracos, oportunidades de melhoria e ameaças ao negócio, ajudando ao mesmo tempo a caracterizar o ambiente organizacional e apoiar ações futuras.

Da mesma forma, o BSC - Balanced ScoreCard é uma ferramenta que possibilita identificar e sinalizar os principais indicadores a serem considerados pela organização, de forma que o balanceamento de indicadores essenciais possibilita o cumprimento de metas e estratégias. Como ferramenta de controle, o BSC permite a visualização do efeito do processo decisório, de sorte que se assinalam as prioridades competitivas à organização.

Uma vez identificado o ambiente, tendo um posicionamento mapeado e claro, o gestor parte para definir os valores da organização, interna e externamente, identificando a imagem e percepção sob diferentes óticas do mercado e dos elementos que o compõe.

O conhecimento dos elementos internos e externos ao ambiente organizacional, das forças competitivas e dos meios que dispõe para atingir o objetivo proposto, gera uma base de conhecimentos elencados à disposição do gestor, para que proceda à elaboração de um planejamento, que pode ser facilitado se adotada a visão de desenvolvê-lo sob a ótica de projetos.

Referenciando a base do conhecimento de gerenciamento de projetos, o PMI (2004, p.41) enfatiza que planejamento é o conjunto de processos que define e refina os objetivos e planeja a ação necessária para alcançar os objetivos e o escopo para os quais o projeto foi realizado.

Segundo Cleland (2002), o planejamento deve ser desenvolvido em função de três conceitos: requisitos, diretrizes e responsabilidades. $\mathrm{O}$ autor considera como requisito a 
compreensão das exigências do sistema e saber o que pode ser traduzido do plano de projeto para a situação de trabalho. Como diretrizes, cita a qualidade, o cronograma, o estabeleciemento dos objetivos do projeto, dos custos, da execução da seqüência do planejamento, da descrição dos parâmetros técnicos, da apresentação do plano de trabalho, principalmente do pessoal, o cálculo dos custos e consequentemente dos orçamentos, a identificação e registro dos fatos do projeto, das premissas, dos problemas e propostas de solucioná-los, dos mecanismos de controle e como documentá-los, do detalhe do planejamento e da necessidade de considerar as interfaces e dependências do projeto.

Como responsabilidades, Cleland deixa claro que a identificação dos papéis e responsabilidades devem ser apicadas e relacionadas à equipe; à alta administração e aos gerentes funcionais.

A sociedade do conhecimento, amplamente difundido por Reis (2000) e Hope e Hope (2000), descrevem os capitais intelectual, ambiental, estrutural e de relacionamento como os principais a serem considerados em uma organização. Desta forma, os processos de planejamento podem ser agrupados por áreas de conhecimento (Valle et.al., 2007), como mostra o quadro 1.

\begin{tabular}{|l|l|}
\hline \multicolumn{1}{|c|}{ Área de Conhecimento } & \multicolumn{1}{c|}{ Processos de Planejamento } \\
\hline Integração do gerenciamento de projetos. & Desenvolver o plano de gerenciamento do projeto. \\
\hline Gerenciamento do escopo do projeto. & $\begin{array}{l}\text { Planejar o escopo, definir o escopo e criar a EAP } \\
\text { (Estrutura Analítica do Projeto). }\end{array}$ \\
\hline Gerenciamento do tempo do Projeto. & $\begin{array}{l}\text { Definir atividades, efetuar o seqüênciamento das } \\
\text { tarefas bemo como dos recursos, da duração } \\
\text { (cronograma). }\end{array}$ \\
\hline Gerenciamento de custo do projeto. & Estimar e orçar os custos \\
\hline Gerenciamento da qualidade. & Planejar a qualidade do projeto \\
\hline Gerenciar os Recursos Humanos do projeto. & Planejar os Recursos Humanos \\
\hline Gerenciamento das comunicações do projeto. & Planejar as comunicações \\
\hline Gerenciamento dos riscos do projeto. & $\begin{array}{l}\text { Planejar os riscos, identificar riscos, analisar qualitativa } \\
\text { e quantitativamente os riscos, planejar as respostas a } \\
\text { riscos. }\end{array}$ \\
\hline Gerenciamento de aquisições do projeto. & Planejar compras e aquisições, planejar contratações \\
\hline
\end{tabular}

Quadro 1 - Processos de planejamento agrupados por áreas do conhecimento.

Fonte: Valle et.al. (2007, p.93)

Neste processo de agrupamento das áreas do conhecimento, a situação ideal seria contar com o envolvimento do usuário (cliente e fornecedor - internos e externos) desde a fas inicial até final deste ciclo, ajudando a satisfazer os objetivos propostos, apresentando o projeto documentado e aceito pelo envolvimento das esferas administrativas empresariais.

REBRAE. Revista Brasileira de Estratégia, Curitiba, v. 1, n. 3, p. 343-352, jan./abr. 2008 
Considerando-se, ainda, a questão de inovação e de melhorias sempre presentes em novos projetos ou readaptações de projetos antigos, alguns estudiosos japoneses propõem o Kaikaku Project Management, KPM, sendo Kaikaku tem sentido de evolução e reúne outros três "ks": Kakusin (inovação), Kahatsu (desenvolvimento) e Kaizen (melhoria), mais especificamente a unidade sinergética a ser desafiada e ligada à estratégica de alto nível das corporações (OHARA; ASADA, 2009, p.17-19). A Figura1 ilustra o relacionamento entre tais termos.

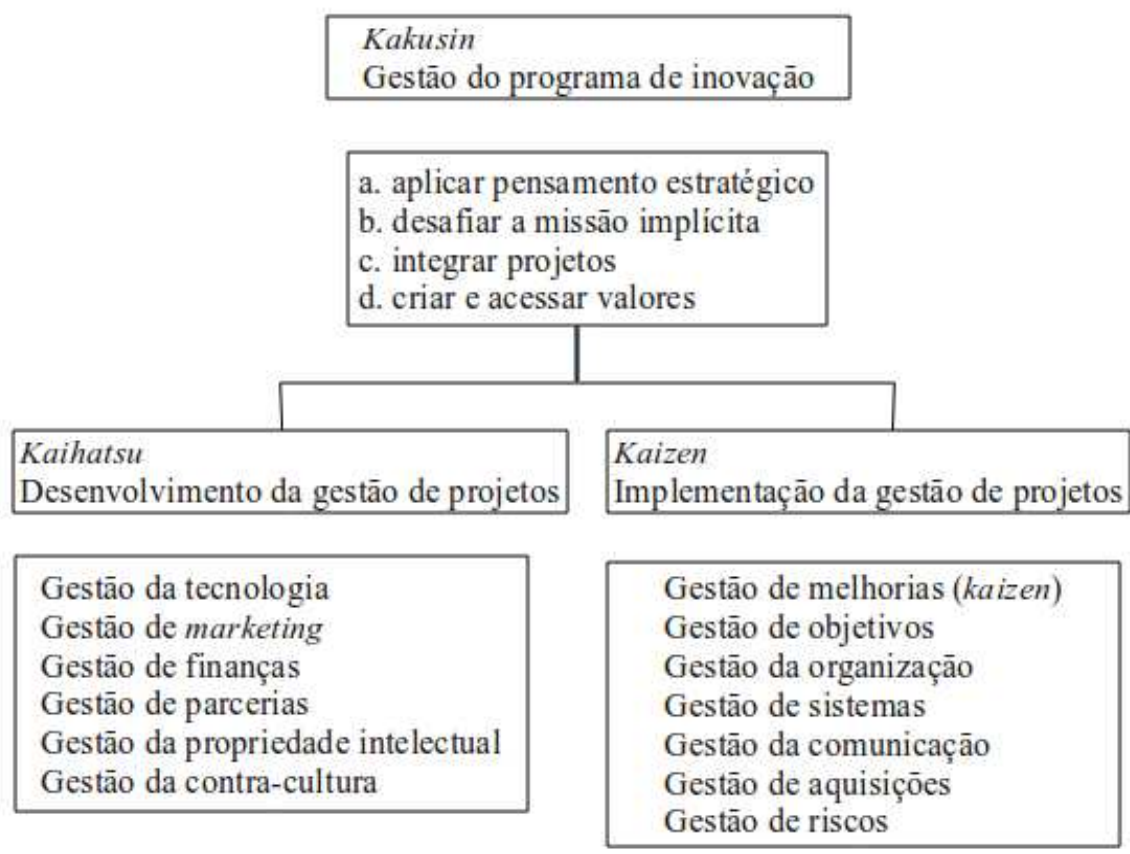

Figura 1 - The KPM knowledge framework - estrutura de conhecimento do método KPM de gerenciamento de projetos

FONTE: OHARA; ASADA, 2009, p.20

\section{O PROCESSO DE PLANEJAMENTO}

Um conjunto de práticas em gerência de projetos levantado pelo PMI (Project Management Institute) e que constitui a base da metodologia de gerência de projetos da instituição é referenciado por meio de práticas compiladas na forma de um guia, o guia do conjunto de conhecimentos em gerenciamento de projetos, ou Guia PMBOK (Project Management Body of Knowledge).

Além das nove áreas de conhecimento disponíveis no guia PMBOK, há outra abordagem que pode ser levada em consideração ao processo de planejamento, enfatizado 
pelo gerenciamento de processos que, de acordo com Varvakis (2001) é a definição, análise e melhoria contínua dos processos, com objetivo de atender as necessidades e expectativas dos clientes.

Conhecendo o processo como uma série de tarefas logicamente inter-relacionadas, que quando executadas produzem resultados esperados, compostas e organizadas por pessoas, equipamentos, informações, esforços e processos, que fazem parte do diagnóstico e, quando agregados à identificação dos valores organizacionais, à análise ambiental da empresa, e aos capitais do conhecimento - capital intelectual, capital de relacionamento e capital estrutural constituem-se a base para o planejamento organizacional.

Quando o gestor define a visão organizacional, define a idéia lógica, a prospecção abstrata para atingir os objetivos da organização. Derivada da visão vem a declaração da missão, que é a base de existência da organização, é a resposta ao questionamento que fazem aos líderes sobre qual é o negócio da empresa. A resposta deve ser clara, concisa, precisa e direta, de modo a figurar e proporcionar o entendimento rápido das pessoas que são e compõem a empresa.

Definidas a visão e missão organizacional, fica claro o estabelecimento de estratégias para atingir o objetivo organizacional. De acordo com Porter (2005), estratégias são aquelas que mudam os objetivos, produtos, serviços ou relações ambientais de uma empresa, fornecendo vantagens de mercado significantes, e que requerem novos padrões de comportamento organizacional.

A definição de uma estratégia engloba a (re)definição do direcionamento de táticas, estabelecendo incialmente o escopo do projeto, de modo que não restem dúvidas quanto ao quê deve ser realizado, seguindo-se da definição clara do prazo (ou cronograma) a ser cumprido; o orçamento ou verba disponível para execução das atividades; as pessoas envolvidas e arregimentadas nos processos bem como dos recursos materiais que estas usarão em prol das suas ações; bem como do local claramente definido e selecionado de forma a proporcionar condições úteis e favoráveis ao cumprimento das ações previstas (figura $1)$.

Antecedendo a definição do escopo é necessário, conforme já explicitado, que se proceda a uma análise ambiental e das informações que vão subsidiar o processo decisório.

Devem compor o conjunto de táticas, que compõem uma estratégia cuidadosamente elaborada a partir da definição de uma missão, a referência ou descrição detalhada do plano 
de atividades a serem executas pelas pessoas, deixando claro os mecanismos de monitoramento e controle a que os processos serão submetidos.

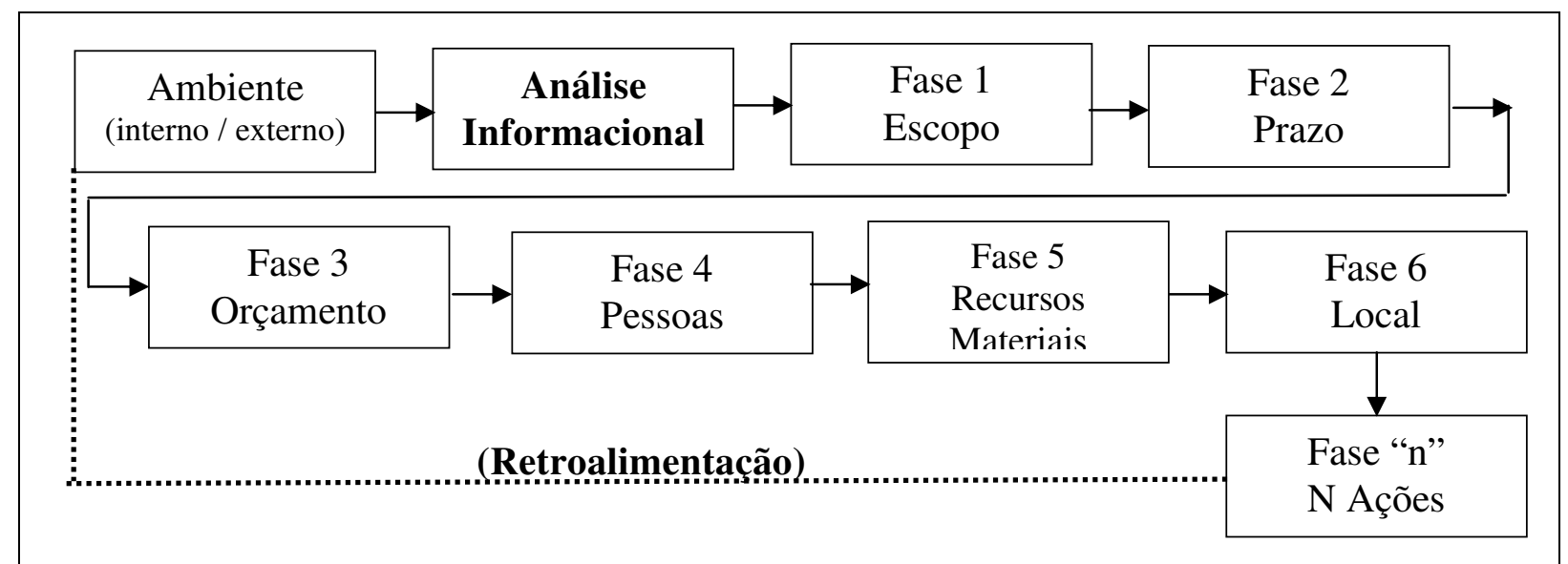

Figura 2 - Fases definidas no processo inicial do planejamento.

Como a Figura 2 permite observar, o processo inicia-se a partir da análise ambiental (usando-se das técnicas já comentadas, SWOT, BSC etc.) que gerará informações subsidiárias ao processo decisório, num segundo momento, deve-se proceder à análise das informações, buscando o melhor alinhamento com a estratégia da organização permitindo que se defina corretamente o escopo do planejamento para, então, definir-se os prazos para execução de cada fase. Definindo-se esse conjunto inicial necessário estabelece-se um cronograma (ou aprazamento) para a consecução das tarefas, definem-se os recursos necessários para a execução do projeto (financeiros, humanos e materiais), o espaço físico (o locus) onde acontecerão as atividades e, finalmente, inicia-se a execução que, ao ser controlada, gerará subsídios para novas análises ambientais e informacionais, retroalimentando o processo.

Ao conjunto de atividades, estão elencadas uma série de tarefas. Tarefas são ações que devem ser rigorosamente efetuadas de acordo com o planejado, ou seja, com o planejamento.

Neste ponto encontra-se o tema gerenciamento de processos, que engloba o estudo pormenorizado das ações. Fluxogramas, diagramas de blocos, árvores de decisão entre outras ferramentas podem ser utlizadas para facilitar a visualização das ações com o objetivo de conhecer, identificar e capturar oportunidades de melhorias, como por exemplo, melhora nas comunicações, na otimização de recursos (tangíveis e/ou intangíveis), maior envolvimento dos funcionários em todos os níveis, entre outros. 
A busca incessante de melhorias reflete-se então na mudança cultural da organização, na motivação, na criatividade e no poder de efetuar trabalhos cada vez mais elevados em termos de eficiência e eficácia, perenes e sustentáveis ao decorrer do tempo.

As ações, quando monitoradas, ou seja, controladas por meio de gráficos, relatórios, conformidades, padrões pré-estabelecidos, levam à identificação da ação como sendo uma boa prática a ser estabelecida. Por exemplo, os indicadores de qualidade e idealizadas na influência gerencial por Dinsmore (1989).

De acordo com Garvin (1988), Hauser e Clausing (1988), a qualidade requerida pelo estabelecimento correto de processos gerenciais, seu constante monitoramento e aplicação de melhorias contínuas mediante o gerenciamento de processos, elevam o padrão organizacional e, como conseqüência, a competitividade e permanência no mercado.

Quando um processo é considerado como detentor de qualidade, significa que as metas estipuladas no processo de planejamento podem ser atingidas. Tendo um conjunto de metas atingidas, de forma plena, aceitável, remete-se ao direcionamento dos objetivos organizacionais.

O cumprimento dos objetivos constitue-se o alvo organizacional. É a consumação qualitativa do processo de planejamento e considera por satisfeita o cumprimento dos requisitos e necessidades dos elementos (principalmente clientes e fornecedores), internos e externos da organização.

\section{CONSIDERAÇÕES AO PLANEJAMENTO E AO PROJETO}

O planejamento é bem sucedido? Seu projeto atinge os objetivos? A resposta a este questionamento fica evidenciada quando cada um dos processos planejados consegue produzir todas as entregas planejadas; se foi completado dentro do cronograma; executado dentro do orçamento; sendo entregue nas especificações funcionais, de qualidade e de performance; se alcançou todas as metas, objetivos e propósitos e se atingiu todas as expectativas das partes interessadas.

Além disso, Haw (2006) deixa claro que o projeto tem sucesso se está alinhado com os objetivos da organização; se conta com apoio efetivo da alta administração; tem uma liderança efetiva; todas as partes interessadas estão de acordo com o propósito, metas e objetivos; expectativas são continuamente gerenciadas; escopo, abordagem e entrega do 
projeto são claramente definidas e acordadas; se o papel e a responsabilidade de cada membro da equipe são claramente comunicados e entendidos; se o cronograma é realista e acordado entre as partes; como comunicações são consistentes, efetivas e focadas no entendimento; com seu progresso medido frequentemente em relação a uma linha de base; se está alinhado a um forte senso de colaboração e trabalho em equipe sendo alcançado; tendo suas expectativas e mudanças relacionadas ao escopo, cronograma, custos e qualidade gerenciados cuidadosamente; tendo seus recursos capacitados e disponíveis quando necessários; dando a oportunidade para que a equipe do projeto identifique proativamente seus riscos e tratar vulnerabilidades diminuindo a sua exposição.

Segundo Valle et.al. (2007, apud Wysocki, 2003), preferencialmente, o processo de planejamento não deve contemplar erros, mas estes podem surgir, principalmente quando há o não-entendimento do alinhamento do projeto com a organização; há falta de gerenciamento das expectativas de ambas as partes; ou ainda outros fatores como falta de acordo das partes nos fatores críticos de sucesso (aqueles que a organização precisa possuir para ser vencedora); falta de cronograma realista; falta de comunicação, de responsabilidades dos membros da equipe; falta da identificação preliminar de riscos para o projeto; falta de definição de requisitos e escopo e, ainda, existência da inadequação do gerenciamento e liderança da equipe do projeto.

\section{A INFORMAÇÃO E O PLANEJAMENTO}

Embora implícita nas entrelinhas do que se escreveu até aqui, a análise informacional é requisito indispensável para o processo de planejamento, como proposto no PMBOK.

O processo decisório é uma das atividades administrativas mais importantes. Tanto que se afirma sempre ser a qualidade das decisões tomadas diretamente proporcional à qualidade das informações disponíveis durante o processo decisório. Portanto, é imprescindível compreender o papel das informações para a administração, onde elas estão disponíveis e como devem ser gerenciadas para que a qualidade do processo decisório seja melhorada. Formular estratégias implica, necessariamente, em análise ambiental interna e externa, o que vai gerar um volume significativo de dados que deverão ser transformados em informações úteis para a elaboração das estratégias competitivas. Assim, o adequado 
gerenciamento das informações é essencial para suportar tanto o processo decisório quanto a formulação das estratégias competitivas.

As bases de trabalho da gestão da informação são "conhecimentos, informações e dados registrados e explícitos em diferentes mídias ou implícitos nas experiências não declaradas de pessoas" (UFPR, 2007). Isso implica conhecer o que é informação, como ela se desenvolve, sua importância para as organizações e como ela pode ser utilizada no processo decisório e/ou na formulação de estratégias competitivas, com tudo o que isso implica.

Ocorre que a atividade administrativa, nos dias atuais, não pode ser conduzida como foi no passado, não podendo prescindir do suporte de sistemas de informação adequados a uma gestão moderna e focados na competitividade. Ou seja, a partir do suporte da tecnologia da informação, a gestão da informação tem condições de gerenciar novos modelos de organização muito mais voltados a processos, que abandonam velhas estruturas hierárquicas. Isso ocorre porque os limites espaciais e temporais já não ditam o ritmo do trabalho, nem o local de sua execução, sobretudo naquelas atividades que independem de máquinas e equipamentos para sua execução, uma vez que "a empresa virtual não pode mais ser situada precisamente. Seus elementos são nômades, dispersos e a pertinência de sua posição geográfica decresceu muito" (LÉVY, 1996: 19).

Além de poder contribuir para a estratégia das organizações, a gestão da informação pode contribuir, também, de forma tático-operacional, possibilitando mudanças significativas na forma como as organizações são gerenciadas. Pois, ainda segundo Lévy (1996: 18)

\footnotetext{
"o centro de gravidade da organização não é mais um conjunto de departamentos, de postos de trabalho e de livros de ponto, mas um processo de coordenadas espaço-temporais da coletividade de trabalho e de cada um de seus membros em função de diversas exigências".
}

Isso conduz à necessidade de gerir adequadamente esse "processo de coordenadas espaço-temporais", de forma que as diferentes exigências dos membros da coletividade de trabalho sejam atendidas em termos de qualidade, relevância, tempo e utilidade das informações recebidas por cada um dos interessados.

Num passado não muito distante, e ainda atual em muitas organizações, a existência de um Centro de Processamento de Dados - CPD ditava as regras de como as informações eram obtidas, processadas e distribuídas pela organização como um todo. Porém, com o advento do microcomputador, os usuários passaram a ter acesso às informações antes 
centralizadas no computador central e, com isso, criaram-se os Centros de Informações, "onde os usuários, dispondo de novas ferramentas têm certa liberdade para criar seus próprios relatórios e pequenos sistemas" (ARAÚJO, 2004, p. 156). Isso durou pouco tempo, porque o volume de trocas com o macro-ambiente organizacional cresceu assustadoramente exigindo mais do que os Centros de Informações (ARAÚJO, 2004), conduzindo à necessidade de um melhor gerenciamento das informações organizacionais.

O gestor deve pesquisar e entender perfeitamente a relação existente entre o ambiente e os recursos disponíveis na organização para agir corretamente e investir nos pontos mais fortes da empresa. Muitas vantagens são fáceis de serem copiadas; o difícil é sustentá-las. Uma vantagem durável normalmente deriva de habilidades humanas selecionadas, capacidades logísticas, bases de conhecimento e outras forças do serviço que os competidores não conseguem reproduzir. É neste ponto que a informação pode ser indispensável para o processo de planejamento, de modo que seja possível "...fazer bem feito da primeira vez e, fazer melhor da segunda..." (PARASURAMAN, BERRY, 2002); ou, na visão de Senge (1990, p. 87), os problemas de hoje vêm das "soluções" de ontem.

Portanto, pode-se resumir com o quadro a seguir, onde se apresentam elementos que devem estar presentes em um projeto para que o mesmo possa ser concretizado com sucesso.

1. análise ambiental (interna e externa) para levantamento de informações;

2. definiçãa adequada e precisa do escopo;

3. boa definição e priorização das razões para se fazer o projeto;

4. entendimento dos riscos potenciais que podem afetar o projeto;

5. um bom plano de gerenciamento desses riscos;

6. um plano de execução logo após a definição da estratégia do projeto;

7. mecanismos para medir o desempenho, em cada fase do projeto, de cada um dos indicadores associados aos objetivos;

8. início imediato da execução de um plano de recuperação quando detectadas discrepâncias (realizado em comparação ao projetado);

9. incorporação rápida de cada mudança aprovada de escopo;

10. relatórios de status periódicos que atendam as necessidades dos interessados no projeto.

\section{Quadro 2 - Componentes de um Projeto de Sucesso}

Fonte: adaptado de Kimons (2001)

REBRAE. Revista Brasileira de Estratégia, Curitiba, v. 1, n. 3, p. 343-352, jan./abr. 2008 
Como é possível perceber, todos os dez elementos do quadro são baseados em informações e, assim, é necessário que esse processo seja adequadamente gerenciado.

\section{PROCEDIMENTOS METODOLÓGICOS E RESULTADOS}

Para este trabalho, adotou-se a abordagem do PMI de gerenciamento de projetos visando introduzir uma sequência lógica ao ato de planejar uma organização, considerando os principais elementos que compõem o processo de planejamento. Para tanto, definiu-se uma ordem de importância relativa a cada etapa e aos resultados esperados em cada uma, acrescendo-se a necessária e fundamental análise informacional prévia ao processo.

O acréscimo de análise informacional prévia implicou na utilização de ferramentas de análise ambiental (interna e externa) mas, sobretudo de contato com os usuários das informações resultantes do processo para que, ao final do processo, fosse possível fornecer a esses usuários as informações realmente relevantes à tomada de decisão.

Para a realização do trabalho estudou-se uma empresa distribuidora de produtos farmacêuticos, de médio porte, que realiza anualmente um processo de planejamento conforme a metodologia proposta pelo Guia PMBOK (Project Management Body of Knowledge). Para este estudo, sugeriu-se a inclusão de análise informacional prévia ao método proposto pelo Guia PMBOK. Após a elaboração do planejamento, realizaram-se entrevistas com os responsáveis pelo planejamento da empresa e com os usuários do plano e todos, sem exceção, manifestaram satisfação com a melhoria obtida no processo.

Quanto aos procedimentos metodológicos, adotou-se uma pesquisa ação, por meio de um estudo de caso único, conduzida durante 14 meses, tendo sido realizada uma entrevista semi estruturada prévia com os responsáveis pelo processo de planejamento da empresa. Após, realizou-se nova entrevista e, ainda, estudo e solicitou-se que conversassem com os usuários do documento resultante do planejamento para esclarecer os propósitos e resultados a serem obtidos.

Os responsáveis pelos diferentes departamentos da empresa são os usuários finais do processo e, muitos deles, são também membros da equipe de planejamento. A esses usuários pediu-se que definissem suas necessidades informacionais (entendidas como as características e informações) mais relevantes ao seu dia-a-dia. Após essas definições se iniciou efetivamente 
o processo de planejamento, considerando-se as necessidades de informações identificadas nessa etapa.

O planejamento resultante desse processo foi comparado com o processo anteriormente utilizado e, como resultado, verificou-se que o mesmo apresentou melhorias significativas, como: melhor divulgação entre os atores envolvidos no processo; definição de estratégias, objetivos e metas com maior clareza; melhor compreensão das estratégias, objetivos e metas, por todos os funcionários da empresa (resultado da melhor clareza do processo); maior facilidade de mensuração dos resultados obtidos após aplicação, decisões mais alinhadas à estratégia, entre outras melhorias.

\section{CONCLUSAO}

Ao adotar-se a metodologia proposta, verificou-se que a organização obteve ganhos significativos, uma vez que o processo de planejamento é concluído indicando com eficiência e eficácia se os objetivos propostos podem ser atingidos dentro do prazo, do orçamento e com os recursos tangíveis e intangíveis mapeados.

Conclui-se que a análise e os estudos dos principais elementos que compõe o projeto devem ser identificados, analisados, levados ao conhecimento das pessoas que interagem no processo, capturando e desenvolvendo as oportunidades de melhorias a cada passo de sua execução. Desta forma, tem-se um processo de gestão focado nos procedimentos que agregam valor, com continuidade da prestação dos serviços e produtos da organização ao longo do tempo.

Por meio de um procedimento metodológico claro, embasado em informações prévias com a necessária qualidade, o planejamento estratégico pode ser aprimorado continuamente seguindo-se as etapas propostas na figura um, de forma que o processo seja dinâmico e coerente com a realidade ambiental em que as organizações estão inseridas.

O contato posterior, com os gestores das principais áreas funcionais da organização, permitiu observar que as decisões estavam mais alinhadas à estratégia organizacional aumentando a eficácia da utilização dos recursos da empresa.

A adoção da metodologia do PMI também para o gerenciamento dos projetos resultantes do planejamento estratégico, demonstrou ser de grande utilidade para as decisões tático-administrativas e operacionais, validando o processo e melhorando o alinhamento 
estratégico. Isso é decorrência do fato que a garantia da melhoria dos processos e dos objetivos e metas alcançadas é reflexo do comportamento e maturidade da gerência, dos fatores que influenciam a tomada de decisão, tendo sempre o profissional a avaliação e resposta final da ação a ser executada.

Também é possível inferir que a aplicação da metodologia proposta em organizações de pequeno porte pode ser uma importante ferramenta para contribuir com a diminuição das taxas de mortalidade verificadas nesse tipo de organização, uma vez que a inexistência de estratégia tem sido apontada como uma das causas de mortalidade nessas organizações.

Por fim, recomenda-se a análise de um maior número de organizações, de diferentes ramos de atividade para que seja possível validar a metodologia do PMI, acrescida da análise informacional prévia, como uma prática de planejamento estratégico a ser incorporada pelas empresas.

\section{REFERÊNCIAS}

ARAÚJO, L. C. G. de. Teoria Geral da Administração: aplicação e resultados nas empresas brasileiras. São Paulo: Atlas, 2004.

CLELAND, D.; IRELAND, L. Gerência de projetos. Rio de Janeiro: Reichmann \& Affonso, 2002.

DINSMORE, P. C. Poder e influência gerencial: além da autoridade formal. Rio de Janeiro: COP, 1989.

GARVIN, D. A. Managing quality: the strategic and competitive edge. New York: Harvard Business School, 1988 .

HARWARD COLLEGE. Project management manual. Harward business school, 1997.

HAUSER, J.R.; CLAUSING, D.. The house of quality. Harvard Business Review, v.66, n. 3, 1988.

HAW, S.. Marco Polo in China. Oxford: Routledge, 2006.

HOPE, J.; HOPE, T. Competindo na Terceira Onda: Os Dez Mandamentos da Era da Informação. Rio de Janeiro: Campus, 2000.

KIMONS, R. L. Picking projects for profitability. Revista PMNetwork, de dezembro de 2001

LÉVY, P. O que é o virtual? São Paulo: Editora 34, 1996.

LIMMER, C. V. Planejamento, orçamento e controle de projetos e obras. Rio de Janeiro: Livros Técnicos e Científicos, 1997.

OHARA, S.; ASADA, T. Japanese project management. KPM: Innovation, development and improvement. Coleção japanese management and international studies, Vol. 3. Singapore: World Scientific Publishing Co., 2009.

PARASURAMAN A.; BERRY, L. L. Serviços de Marketing - Competindo através da qualidade. São Paulo: Maltese, 2002.

PMI. Guia PMBOK - Um guia do conjunto de conhecimentos em gerenciamento de projetos. ANSI/PMI 99001. 2004.

PORTER, M. Estratégia competitiva: técnicas para análise de indústrias. Rio de Janeiro: Campus, 2005.

REIS, L. dos. Estratégia Empresarial: Análise, Formulação e Implementação. Lisboa-Portugal: Editora Presença, 2000.

REBRAE. Revista Brasileira de Estratégia, Curitiba, v. 1, n. 3, p. 343-352, jan./abr. 2008 
SENGE, P. A quinta disciplina. 7a ed. São Paulo: Nova Cultural, 1990.

UFPR. UFPR: Cursos e Profissões. Assessoria de Comunicação Social. Curitiba: UFPR - Universidade Federal do Paraná, 2007.

VAlle, A. B. do; SOARES, C. A. P.; FINOCCHIO JR., J.; SILVA, L. de S. F. Fundamentos do gerenciamento de projetos. Rio de Janeiro: FGV, 2007

VALERIANO, D. L. Gerência em projetos: pesquisa, desenvolvimento e engenharia. São Paulo: Makron Books, 1998.

VARVAKIS, G. Gerenciamento de Processos. (Apostila do Curso de Mestrado em Engenharia da Produção). Florianópolis: Imprensa UFSC, 2002.

WYSOCKI, R. Project management process improvement. Norwood: Artech House, 2003.

Recebido: 29/06/2007

Received: 06/29/2007

Aprovado: 08/11/2007

Approved: 11/08/2007

REBRAE. Revista Brasileira de Estratégia, Curitiba, v. 1, n. 3, p. 343-352, jan./abr. 2008 